\title{
Battalion Chief Dies From Aortic Dissection After Physical Fitness Training - Missouri
}

\section{Executive Summary}

On January 1, 2015, a 41-year-old male career battalion chief (“BC”) worked a 24-hour shift with no emergency calls. On January 2, the off-duty BC performed physical fitness training at a gym. Later that evening, he experienced chest pain and was evaluated in the local emergency department (ED) where musculoskeletal chest wall pain was diagnosed and he was released. He worked two subsequent 24-hour shifts on January 3 and 5, and assisted with search dog training for 2 hours on January 7, 2015. The evening of January 7, the BC's wife was awakened at about 2300 hours by a loud snoring type of sound. She could not awaken the BC and called 911; an ambulance with paramedics responded. Despite advanced life support treatment at the scene, in the ambulance, and inside the hospital's ED, the BC was pronounced dead at 0051 hours on January 8, 2015.

The death certificate and autopsy report, both completed by the Deputy Medical Examiner, listed "ruptured aortic dissection" as the cause of death. It is unlikely the exertion during the physical fitness training performed on January 2, 2015 initiated the BC’s aortic dissection.

\section{Key Recommendations}

The following recommendations would not have prevented the BC's death, but NIOSH investigators include them to address general safety and health issues and to prevent future cases of sudden cardiac death.

- Provide annual medical evaluations to all fire fighters in accordance with National Fire Protection Association (NFPA) 1582, Standard on Comprehensive Occupational Medical Program for Fire Departments.

- Discontinue preplacement screening lumbar spine $x$-rays unless clinically indicated.

The National Institute for Occupational Safety and Health (NIOSH), an institute within the Centers for Disease Control and Prevention (CDC), is the federal agency responsible for conducting research and making recommendations for the prevention of work-related injury and illness. In 1998, Congress appropriated funds to NIOSH to conduct a fire fighter initiative that resulted in the NIOSH "Fire Fighter Fatality Investigation and Prevention Program" which examines line-of-duty-deaths or on duty deaths of fire fighters to assist fire departments, fire fighters, the fire service and others to prevent similar fire fighter deaths in the future. The agency does not enforce compliance with State or Federal occupational safety and health standards and does not determine fault or assign blame. Participation of fire departments and individuals in NIOSH investigations is voluntary. Under its program, NIOSH investigators interview persons with knowledge of the incident who agree to be interviewed and review available records to develop a description of the conditions and circumstances leading to the death(s). Interviewees are not asked to sign swom statements and interviews are not recorded. The agency's reports do not name the victim, the fire department or those interviewed. The NIOSH report's summary of the conditions and circumstances surrounding the fatality is intended to provide context to the agency's recommendations and is not intended to be definitive for purposes of determining any claim or benefit. For further information, visit the program website at www.cdc.gov/niosh/fire or call toll free 1-800-CDC-INFO (1-800-232-4636). 


\section{Introduction}

On January 8, 2015, a 41-year-old male career BC died from a dissected aorta. NIOSH was notified of the fatality by the U.S. Fire Administration on January 9, 2015. NIOSH contacted the affected FD on January 9, 2015, to gather additional information and on February 17, 2015, to initiate the investigation. On February 23, 2015, a safety and occupational health specialist from the NIOSH Fire Fighter Fatality Prevention and Investigation Program investigated the incident.

During the investigation, NIOSH personnel interviewed the following people:

- Fire Chief

- BC's wife

NIOSH personnel reviewed the following documents:

- FD standard operating procedures

- FD annual report for 2014

- Search and rescue medical evaluation report

- Emergency medical service (ambulance) report

- Hospital ED reports (from January 2 and 7, 2015)

- Death certificate

- Autopsy report

\section{Investigation}

On January 1, 2015, the BC worked his 24-hour shift but did not respond to any emergency calls. During the shift, he performed daily apparatus check and office duties. After going off duty on January 2, 2015 at 0700 hours, the BC went home. At about 1030 hours, the BC and his wife exercised at a local gym for about 30 minutes. While eating dinner that evening (1700 hours), the BC remarked that he had not felt well all day. A few hours later (2040 hours), the BC remarked that he was having chest pain and needed to go to the hospital.

Arriving at the ED at 2056 hours, the BC complained of non-radiating substernal chest pain/pressure but no heavy sweating, nausea, shortness of breath, or syncope. His initial vital signs included a blood pressure of 169/83 millimeters of mercury (mmHg), a pulse rate of 84 beats per minute, and a respiratory rate of 18 breaths per minute. His electrocardiogram (EKG) was unremarkable and his cardiac enzyme testing revealed normal levels of creatine kinase, creatine kinase-myocardial band, and troponin I, suggesting he was not having a heart attack. It was noted that the BC's troponin I d-dimer level was elevated (921 nanograms per milliliter [normal is 0-450]). The d-dimer is a blood test that measures a substance that is released when a blood clot breaks up. It is used to help diagnose a bloodclotting condition. These conditions include: (1) deep vein thrombosis (a condition in which a blood clot [thrombus] forms in the deep veins of the legs, pelvis, or arms, (2) pulmonary embolism (a 


\section{Battalion Chief Dies From Aortic Dissection After Physical Fitness Training - Missouri}

condition in which blood flow in a pulmonary artery is suddenly blocked), or (3) disseminated intravascular coagulation (DIC) (a condition that prevents a person's blood from clotting normally). A computed tomography (CT) chest angiogram reported "no evidence of pulmonary embolism and no evidence of a thoracic aortic dissection or aneurysm.” The BC was diagnosed with musculoskeletal chest wall pain and prescribed a non-steroidal anti-inflammatory agent (Naproxen ${ }^{\circledR}$ ) and a muscle relaxant (Flexeril $\left.{ }^{\circledR}\right)$. The BC decided to take an over-the-counter pain reliever (Aleve ${ }^{\circledR}$ ) and did not fill the Flexeril ${ }^{\circledR}$ prescription due to work restrictions associated with its use.

The next day, January 3, 2015 the BC reported for duty for his 24-hour shift. After performing apparatus check and office duties, he responded as the incident commander to two calls (a medical call and a controlled burning investigation call). At 0700 hours on January 4, the BC went home and performed household chores.

On January 5, 2015, the BC reported for his 24-hour shift. After performing apparatus check and office duties, he responded to one mutual aid call at 0945 hours to search for victims at a structure fire with his search dog. Since the building was unstable, he was released from the scene at 1200 hours and returned to his fire station. At 1635 hours, he responded to a medical call. At 1800 hours the BC responded again to the mutual aid call for the search dog. He remained at the scene until 2300 hours when he returned to his fire station.

At 0700 hours, January 6, 2015, the BC responded to the third mutual aid call for the search dog team. A fire victim was found and the $\mathrm{BC}$ left the scene at 1300 hours and went home. During the remainder of the day, the BC performed household chores.

On January 7, 2015, the BC performed search dog training from 0900 hours to 1130 hours, then went home and performed household chores. Later in the day, he commented to his wife that he had a dry cough and had not felt well all day. At about 2200 hours, the BC went to bed. At 2255 hours the BC was noted by his wife to make a loud snoring sound. When his wife was unable to wake him, she called 911 at 2257 hours.

The ambulance responded, arriving on the scene at 2305 hours. Paramedics found the BC unresponsive, with no pulse, and not breathing. CPR was begun, an oral airway was placed, and a cardiac monitor was applied; it revealed pulseless electrical activity. Oxygen was administered via non-rebreather mask and his heart rhythm reverted to asystole (no heart beat). An intravenous line was placed and cardiac resuscitation medications were administered. The BC was placed into the ambulance, which departed the scene at 2325 hours en route to the ED. En route, there was no positive change in the BC’s clinical status.

The ambulance arrived at the ED at 2328 hours. Inside the ED, the BC was intubated with proper placement of the endotracheal tube via capnography, equal breath sounds, direct visualization, and chest x-ray [Neumar et al. 2010]. Cardiac enzymes were tested, and results were normal. A chest x-ray revealed probable mild cardiomegaly. An EKG noted atrial fibrillation with rapid ventricular response, septal infarction age undetermined, and non-specific ST- and T-wave abnormality. The BC remained 


\section{Battalion Chief Dies From Aortic Dissection After Physical Fitness Training - Missouri}

hypotensive throughout his ED stay along with intermittent pulseless electrical activity heart rhythms that became persistent at 0009 hours. Advanced life support measures continued until 0050 hours, January 8, 2015, when a cardiac ultrasound showed no cardiac activity. At 0051 hours on January 8, 2015, the BC was pronounced dead and resuscitation efforts were discontinued.

\section{Medical Findings}

The death certificate and autopsy report, both completed by the Deputy Medical Examiner, listed "ruptured aortic dissection" as the cause of death. Cardiac findings showed a dissection of the ascending aorta, an enlarged heart, but no coronary artery disease. See Appendix A for additional findings from the autopsy.

The BC's last FD medical evaluation was in 2011. He performed an exercise stress test at which he exercised for 11 minutes on the Bruce Protocol, achieving a VO2 Max of 43.7 milligrams per kilograms per meter squared (12.4 METs). He had a normal blood pressure response to exercise and the test was stopped due to calf pain. A resting EKG was normal.

In January, 2014 he was diagnosed with Stage I hypertension (high blood pressure) during a technical rescue medical evaluation unrelated to the FD. He performed an aerobic capacity step test at which he achieved a VO2 Max of 37.6 (10.7 METs). A resting EKG revealed left ventricular hypertrophy with a left axis deviation. He was not prescribed a blood pressure-lowering medication, opting instead for a trial of increased exercise and improved diet.

The BC was 76 inches tall and weighed 234 pounds, giving him a body mass index of 28.5 kilograms per meters squared [CDC 2014]. The BC had complained of chest pain 5 days prior to this episode.

\section{Fire Department}

At the time of the NIOSH investigation, the FD consisted of three fire stations with 49 career uniformed personnel. The FD served 27,000 residents in a geographic area of 52 square miles. In 2014, the FD responded to 3,476 incidents: 114 fire calls, 2,142 rescue/emergency medical calls, and 1,220 other calls including hazardous conditions, false alarms, service calls, and weather calls.

\section{Employment and Training}

The FD requires career fire fighter applicants to be 18 years of age; be a high school graduate or have the equivalent certificate; have a valid state driver's license; have a Fire Fighter I \& II and either EMT or Paramedic license, and pass a written test (paramedic candidates must pass a mock cardiac arrest), a candidate physical ability test (Appendix B), and an interview prior to a conditional job offer. The only exemption to the Fire Fighter I \& II requirement is the FD may hire a Paramedic without FF I \& II but they must obtain this certification in the first year and are not allowed to take part in fire incidents until that certification is attained.

The FD conducts FF I \& II courses each year for candidates. The potential new hire must then pass a background check and a preplacement medical evaluation (contents described below). The new 


\section{Battalion Chief Dies From Aortic Dissection After Physical Fitness Training - Missouri}

member goes through a 1 week orientation and is then placed on probation for 1 year during which time the member must meet certain requirements of training or they will not retain employment. Training during this period includes map testing, driver training on the ambulance and other first response vehicles with the exception of fire engines, tankers, aerials, and large rescues. The member is also tested on general protocols and procedures, radio usage and protocols, and medical protocols. New members work the following schedule (0700-0700 hours): 24 hours on duty, 24 hours off duty, 24 hours on duty, 24 hours off duty, 24 hours on duty, then are off duty for 4 days. The BC was certified as a Fire Fighter II, Emergency Medical Technician-Paramedic, Fire Officer, Fire Investigator, Fire Instructor, Hazardous Materials Technician, and technical rescue. He had 14 years of fire fighting experience.

\section{Preplacement Medical Evaluations}

The FD requires pre-placement medical evaluations for all applicants. Components of this evaluation include the following:

- Complete medical history

- Physical examination (including vital signs - height, weight, blood pressure, pulse, and respirations)

- Laboratory blood tests (complete blood count, comprehensive metabolic panel, and chemistry)

- Vision test (acuity, color, peripheral fields, and depth perception)

- Hearing test

- Urinalysis

- Urine drug screen

- Chest X-ray (baseline)

- Resting EKG

- Pulmonary function test

- Hepatitis-B antibody/series/booster

- Strength and flexibility tests

- Lumbar spine x-ray (baseline)

The medical evaluation is performed by an FD-contracted physician. Once this evaluation is complete, the physician makes a determination regarding medical clearance for fire fighting duties and forwards this decision to the FD. It is unclear if the BC had a preplacement medical evaluation when he was hired in 2000.

\section{Periodic Medical Evaluations/ Return to Work Medical Evaluations}

Periodic medical evaluations are performed every 3 years for members under age 40, and every 2 years for members age 40 and over. The components are the same as the preplacement medical evaluations except the periodic medical evaluations include a Bruce treadmill test, a coronary risk profile; a urine drug screen is not performed. Again, the medical evaluation is performed by an FD-contracted physician. Once this evaluation is complete, the physician makes a determination regarding medical clearance for fire fighting duties and forwards this decision to the FD.

Medical clearance is required to wear a respirator. Annual SCBA facepiece fit tests are required. 


\section{Battalion Chief Dies From Aortic Dissection After Physical Fitness Training - Missouri}

Members injured on duty and who miss work must be evaluated by the FD-contracted physician who forwards his or her determination for return-to-duty to the FD. Members who have an illness or temporary disability and miss two consecutive shifts must be evaluated by their primary care physician unless the situation dictates otherwise. The primary care providers forward their opinion regarding return-to-duty to the FD who makes the final determination regarding return to work.

\section{Wellness/Fitness Programs}

The FD has a mandatory wellness/fitness program (members must exercise for 30 minutes while on duty), and exercise equipment is available in all fire stations. An annual job performance physical ability test is required for members (see Appendix B). The BC passed his last physical ability test, although no records were kept. The BC exercised regularly and had recently begun a kickboxing exercise regimen.

\section{Discussion}

\section{Aortic Dissection}

The aorta is the major artery that carries blood from the heart to the rest of the body. The aortic wall is composed of three layers in sequence from the lumen proceeding outwards: the intima, medial, and adventitia. Aortic dissection occurs when the blood enters the medial layer typically after a tear in the intima [Chen et al. 1997; Klompas 2002; Januzzi et al. 2004; Creager and Loscalzo 2008; AHA 2015]. Blood expelled from the heart under high pressure (systole) pushes more blood inside the artery wall, further splitting (dissecting) the aorta. Aortic dissection is distinguished from an aortic aneurysm, which is an expansion of the blood vessel due to medial weakening [Chen et al. 1997]. Although they can occur together, dissections can occur in the absence of aneurysms, and not all aneurysms result in dissection. Conditions associated with aortic dissection are listed in Appendix C. Of the risk factors, the BC had hypertension.

Typical presentation for aortic dissection is the sudden onset of severe chest pain radiating to the back frequently associated with sweating [Chen et al. 1997; Klompas 2002; Januzzi et al. 2004; Creager and Loscalzo 2008; AHA 2015]. Nonspecific signs during physical examination are differences among carotid, radial, and femoral pulses [Klompas 2002]; differences in blood pressure between the two arms [Singer and Hollander 1996; Von Kodolitsch et al. 2000]; and a heart murmur heard through a stethoscope. During the BC’s ED visit on January 2, 2015, no heart murmur was heard and no differences in pulses or blood pressure were noted. In addition, according to medical records obtained by the NIOSH investigator, a chest CT did not show a thoracic dissection or aneurysm. However, it is unclear if his chest pain on January 2 was related to his aortic dissection found at autopsy.

\section{Cardiomegaly/Left Ventricular Hypertrophy}

On autopsy, the BC was found to have left ventricular hypertrophy and cardiomegaly. These conditions increase the risk for sudden cardiac death [Levy et al. 1990]. Hypertrophy of the heart's left ventricle is a relatively common finding among individuals with long-standing hypertension, a heart valve problem, or chronic cardiac ischemia (reduced blood supply to the heart muscle) [Siegel 1997]. 


\section{Battalion Chief Dies From Aortic Dissection After Physical Fitness Training - Missouri}

The BC’s hypertension, probably not diagnosed for years, was probably responsible for his left ventricular hypertrophy.

\section{Occupational Medical Standards for Structural Fire Fighters}

To reduce the risk of sudden cardiac arrest or other incapacitating medical conditions among fire fighters, the National Fire Protection Association (NFPA) developed NFPA 1582, Standard on Comprehensive Occupational Medical Program for Fire Departments [NFPA 2013]. This voluntary industry standard provides (1) the components of a preplacement and annual medical evaluation and (2) medical fitness for duty criteria. Even if the FD was conducting annual medical evaluations as recommended by NFPA 1582, it is unlikely this BC's aortic dissection would have been identified.

\section{Recommendations}

The following recommendations would not have prevented the BC's death, but NIOSH investigators include them to address general safety and health issues and to prevent future cases of sudden cardiac death.

Recommendation \#1: Provide annual medical evaluations to all fire fighters in accordance with NFPA 1582, Standard on Comprehensive Occupational Medical Program for Fire Departments. Discussion: Guidance regarding the content and frequency of these medical evaluations can be found in NFPA 1582 and in the International Association of Fire Fighters (IAFF)/International Association of Fire Chiefs (IAFC) Fire Service Joint Labor Management Wellness/Fitness Initiative [IAFF, IAFC 2008; NFPA 2013]. These evaluations are performed to determine fire fighters' medical ability to perform duties without presenting a significant risk to the safety and health of themselves or others. Although the FD is following the components of NFPA 1582, it does not follow the frequency guidance due to budgetary issues. Fully applying NFPA 1582 involves economic repercussions and may be particularly difficult for smaller fire departments to implement. The FD is not legally required to follow the NFPA standard or the IAFF/IAFC guideline.

Recommendation \#2: Discontinue preplacement and routine screening lumbar spine x-rays unless clinically indicated.

Discussion: The FD performs preplacement screening and lumbar spine $x$-rays. While these x-rays may be useful in evaluating individuals with symptoms or existing back problems, the American College of Radiology, American College of Occupational and Environmental Medicine, and NIOSH investigators have concluded that lumbar spine x-rays have no value as a routine screening measure to determine risk for future back injuries [Present 1974; Lincoln et al. 1979; Gibson 1998]. Lumbar spine $\mathrm{x}$-rays are an unnecessary radiation exposure for the individual and an unnecessary expense for the FD.

\section{References}

AHA [2015]. Heart and Stroke Encyclopedia - Aortic Dissection. [http://www.heart.org/HEARTORG/Encyclopedia/Heart- 


\section{Battalion Chief Dies From Aortic Dissection After Physical Fitness Training - Missouri}

Encyclopedia_UCM_445084_Encyclopedia.jsp?levelSelected=1\&title=aortic dissection]. Date accessed: June 2015.

CDC (Centers for Disease Control and Prevention) [2014]. Assessing your weight. [http://www.cdc.gov/healthyweight/assessing/index.html]. Date accessed: June 2015.

Chen K, Varon J, Wender OC, Judge DK, Fromm Jr RE, Sternback GL [1997]. Acute thoracic aortic dissection: the basics. J Emerg Med 15(6):859-867.

Creager MA, Loscalzo J [2008]. Diseases of the aorta. In: Fauci AS, Braunwald E, Kasper DL, Hauser SL, Longo DL, Jameson JL, Loscalzo J, eds. Harrison's principles of internal medicine. 17th ed. New York: McGraw-Hill. pp. 1563-1568.

Gibson ES [1998]. The value of pre-placement screening radiography of the low back. In: Deyo RA, ed. Occupational medicine, state of the art reviews. Philadelphia, PA: Hanley \& Belfus, pp. 91-108.

IAFF, IAFC [2008]. The fire service joint labor management wellness/fitness initiative. 3rd ed. Washington, DC: International Association of Fire Fighters, International Association of Fire Chiefs.

Januzzi JL, Isselbacher EM, Fattori R, Cooper JV, Smith DI, Fang J, Eagle KA, Mehta RH, Nienaber CA, Pape LA [2004]. Characterizing the young patient with aortic dissection: results from the international registry of aortic dissection (IRAD). J Am Coll Cardiol 43(4):665-669.

Klompas M [2002]. Does this patient have an acute thoracic aortic dissection? JAMA 287(17):22622272.

Levy D, Garrison RJ, Savage DD, Kannel WB, Castelli WP [1990]. Prognostic implications of echocardiographically determined left ventricular mass in the Framingham Heart Study. N Engl J Med 323(24):1706-1707.

Lincoln TA, Kelly FJ, Lushbaugh CC, Milroy WC, Voelz GL, Wollenweber HL [1979]. Guidelines for use of routine $\mathrm{x}$-ray examinations in occupational medicine. Committee report.

J Occup Med 21(7):500-502.

NFPA [2013]. Standard on comprehensive occupational medical program for fire departments. Quincy, MA: National Fire Protection Association. NFPA 1582.

Neumar RW, Otto CW, Link MS, Kronick SL, Shuster M, Callaway CW, Kudenchuk PJ, Ornato JP, McNally B, Silvers SM, Passman RS, White RD, Hess EP, Tang W, Davis D, Sinz E, Morrison LJ [2010]. Part 8: Adult advanced cardiovascular life support. 2010 American Heart Association Guidelines for cardiopulmonary resuscitation and emergency cardiovascular care. Dallas, TX: American Heart Association. 


\section{Battalion Chief Dies From Aortic Dissection After Physical Fitness Training - Missouri}

Present AJ [1974]. Radiography of the lower back in pre-employment physical examinations. Conclusions of the ACR/NIOSH Conference, January 11-14, 1973. Radiology 112(1):229-230.

Siegel RJ [1997]. Myocardial hypertrophy. In: Bloom S, ed. Diagnostic criteria for cardiovascular pathology acquired diseases. Philadelphia, PA: Lippencott-Raven, pp. 55-57.

Singer AJ, Hollander JE [1996]. Blood pressure: assessment of interarm differences. Arch Intern Med 156(17):2005-2008.

Von Kodolitsch Y, Schwartz AG, Nienaber CA [2000]. Clinical prediction of acute aortic dissection. Arch Intern Med 160(19):2977-2982.

\section{Investigator Information}

This incident was investigated by the NIOSH Fire Fighter Fatality Investigation and Prevention Program, Cardiovascular Disease Component in Cincinnati, Ohio. Mr. Tommy Baldwin (MS) led the investigation and co-authored the report. Mr. Baldwin is a Safety and Occupational Health Specialist, a National Association of Fire Investigators (NAFI) Certified Fire and Explosion Investigator, an International Fire Service Accreditation Congress (IFSAC) Certified Fire Officer I, and a former Fire Chief and Emergency Medical Technician. Dr. Thomas Hales (MD, MPH) provided medical consultation and co-authored the report. Dr. Hales is a member of the NFPA Technical Committee on Occupational Safety and Heath, and Vice-Chair of the Public Safety Medicine Section of the American College of Occupational and Environmental Medicine (ACOEM).

\section{Disclaimer}

Mention of any company or product does not constitute endorsement by the National Institute for Occupational Safety and Health (NIOSH). In addition, citations to Web sites external to NIOSH do not constitute NIOSH endorsement of the sponsoring organizations or their programs or products. Furthermore, NIOSH is not responsible for the content of these Web sites. 


\section{Battalion Chief Dies From Aortic Dissection After Physical Fitness Training - Missouri}

\section{Appendix A Autopsy Findings}

- Aortic dissection of the ascending aorta

o Beginning 2.3 centimeters $(\mathrm{cm})$ above the aortic valve

0 Extended to the aortic root and extending to the left pulmonary artery

- 920 milliliters of blood in the pericardial cavity suggesting cardiac tamponade

- Cardiomegaly (enlarged heart)

o Heart weighed 670 grams [g]; predicted normal weight is $403 \mathrm{~g}$ [ranges between $305 \mathrm{~g}$ and 531 $\mathrm{g}$ as a function of sex, age, and body weight]) [Silver and Silver 2001]

o Left ventricle thickened (1.9 centimeter [cm])

o Normal at autopsy is $0.76-0.88 \mathrm{~cm}$ [Colucci and Braunwald 1997]

o Normal by echocardiographic measurement is $0.6-1.0 \mathrm{~cm}$ [Connolly and Oh 2012]

- No evidence of coronary artery atherosclerosis or coronary artery thrombus (blood clot)

- Normal cardiac valves

- No evidence of a pulmonary embolus (blood clot in the lung arteries)

- Blood tests for drugs and alcohol were negative.

\section{REFERENCES}

Colucci WS, Braunwald E [1997]. Pathophysiology of heart failure. In: Braunwald, ed. Heart disease. 5th ed. Philadelphia, PA: W.B. Saunders Company, p. 401.

Connolly HM, Oh JK [2012]. Echocardiography. In: Bonow RO, Mann DL, Zipes DP, Libby P, Braunwald E, eds. Heart disease: a text of cardiovascular medicine. 9th ed. Vol. 1. Philadelphia, PA: Elsevier Saunders, p. 216.

Silver MM, Silver MD [2001]. Examination of the heart and of cardiovascular specimens in surgical pathology. In: Silver MD, Gotlieb AI, Schoen FJ, eds. Cardiovascular pathology. 3rd ed. Philadelphia, PA: Churchill Livingstone, pp. 8-9. 


\section{Battalion Chief Dies From Aortic Dissection After Physical Fitness Training - Missouri}

\section{Appendix B \\ Candidate and Annual Physical Ability Test}

1. Stair Climb With High Rise Pack. Pick up the high rise pack at the starting line, place it on the shoulder, then proceed to the interior stairwell from the west-side doorway and ascend the stairs to the fourth floor landing. Then descend the stairwell to the first floor starting line and return to the fourth floor landing. Then descend to the third floor and place the high rise pack on the floor in the designated area. Each step must be touched. Upon completion, proceed directly to the equipment hoist evolution on the third floor balcony.

Penalty: Each time the candidate skips a step, return to the starting line and climb the stairs again.

Justification: Fire fighters are required to carry hose packs and other equipment up stairways to accomplish rescue and fire fighting tasks.

2. Equipment Hoist. Step to the balcony doorway (not on the balcony) and take the rope from the evaluator. Using a rope and a hand-over-hand method, raise approximately 30 pounds of weighted equipment to the balcony platform from a position within the doorway. The evaluator will control the rope and direct the candidate to lift the weighted equipment over the handrail and set it down on the balcony. The candidate will raise his/her hands once the weighted equipment is placed on the floor of the balcony. The candidate will then return the weighted object over the handrail and return to control of the rope (back inside the doorway). The weighted equipment will then be lowered in a controlled manner (hand-over-hand only - no sliding) to the ground. Upon completion of this task the candidate will return to the stairs, pick up the high rise pack and return/descend to the first floor, and place the high rise pack on the ground at the starting line. The candidate may not skip any steps. The candidate will proceed to the breeching evolution on the second floor via the interior stairwell.

Penalty: Each time a candidate skips a step, return to the last landing and descend the stairs again. If the candidate drops the hose, hoist the hose roll again.

Justification: Fire fighters are required to use ropes in raising and lowering tools and equipment for rescue and fire fighting tasks.

3. Breeching Evolution. Proceed to the breeching prop located on the second floor, grab the pike pole with two hands, and begin pulling downward to simulate breeching ceilings. The pike pole will be secured to approximately 25 pounds of weight. The candidate will execute 20 simulated breeches (a simulated breech shall be considered a full downward motion of the pike pole until the weight reaches the pulley and return of the weight to its resting area). Upon completion of the $20^{\text {th }}$ simulated breech, the candidate will exit the second floor via the east side second floor door and down the exterior stairwell to the drill ground. Then proceed to the rescue drag evolution on the east side of the drill area.

Justification: Fire fighters must be able to perform breeching during salvage and overhaul operations. 


\section{Battalion Chief Dies From Aortic Dissection After Physical Fitness Training - Missouri}

4. Ladder Raise. Proceed to the exterior stairwell and take a position under the platform. A 24-foot extension ladder shall be secured in the stowed position upright and the halyard untied. Utilizing proper ladder raise techniques, the fly section shall be fully raised and locked. Once locked, the ladder will then be returned to the stowed position using proper lowering techniques. Proper raising and lowering techniques shall be defined by current IFSTA, Essentials of Firefighting standards. Upon completion of this task the candidate will proceed directly to the attack hose advance evolution.

Justification: Fire fighters are required to raise and lower ground ladders.

5. Forcible Entry/Ventilation Simulation. Use the supplied mallet to move the weighted "sled" section of the Kaiser Machine from one end to the other. The candidate's hands shall be placed no closer than 18-inches to the head of the mallet. No hooking or dragging of the sled is permitted. Only good clean strikes by the mallet to the sled are allowed. No overhead or "round-house" swings will be permitted. The sled must be moved the completed length of the track to complete this task. Upon completion of this task the candidate will proceed directly to the ladder raise located under the exterior stairwell on the east side of the tower.

Penalty: The candidate that continues to swing the sledge hammer improperly after one warning and/or fails to complete the station will be disqualified.

Justification: Fire fighters are required to utilize hand tools such as axes and sledge hammers and must be able to perform these tasks from both the left and right side.

6. Rescue Drag. Proceed to the weighted rescue dummy, grab it by the strap around the upper torso and drag it 50-feet to the finishing point. The rescue dummy shall not be picked up and carried in any manner. Once the body of the rescue dummy crosses the line, it will be rested on the ground and the candidate will proceed to the attack hose advance station.

Justification: Most victims rescued from buildings are dragged not carried by fire fighters.

7. Attack Hose Advance. Pick up the nozzle and extend 150-feet of charged 13/4-inch attack line, past the cone and place it on the ground. The nozzle may be placed over the shoulder or grasped with both hands. The 13/4inch hose will be prearranged on the ground in an accordion pattern for each candidate. Upon completion of this task the candidate will proceed to the aerial climb station.

Justification: Fire fighters are required to advance 13/4-inch lines for fire attack.

8. Aerial Climb. The candidate will be allowed to remove the SCBA once they arrive at the aerial. The timed portion of the assessment will also be stopped at this time. Each candidate will put on a ladder belt and climb to the turntable of the apparatus. A safety line will be placed on the candidate by the evaluator at the turntable. Each candidate will then ascend the aerial ladder 95-feet at 60-degrees. Once they have arrived at the top they will touch the top rung with both hands. The candidate will then descend the aerial ladder.

Penalty: A candidate unable to complete the climb unassisted will be disqualified. 


\section{Battalion Chief Dies From Aortic Dissection After Physical Fitness Training - Missouri}

Justification: Fire fighters are required to climb ladders and operate at heights.

Once all stations have been completed the assessment will be done.

The test is a continuous evolution involving common fire-rescue related tasks that shall be completed consecutively. The candidate is required to work continuously without stopping and successfully complete each task before moving on to the next. There is an overall 15 minute time limit for the course, excluding the Aerial Climb, which shall not be timed. Candidates will be disqualified if they decline to attempt a task and/or exceed the 15 minute time limit. Once the test is started, it may not be interrupted. Any interruption in the test will be cause to restart the test from the beginning at another time. Throughout the processes candidates will be required to wear a bunker coat, helmet, gloves, and an air pack (self-contained breathing apparatus). 


\section{Battalion Chief Dies From Aortic Dissection After Physical Fitness Training - Missouri}

\section{Appendix C \\ Conditions Associated With Aortic Dissection [Chen et al. 1997]}

Male gender

Age $>50$ years

Hypertension

Connective tissue disorders (e.g. Marfan syndrome, Ehlers Danlos syndrome)

Turner syndrome

Noonan syndrome

Coarctation of the aorta

Congenital bicuspid or unicuspid aortic valve

History of cardiac surgery, particularly aortic valve surgery

Granulomatous arteritis

Syphilitic aortitis

Pregnancy

Trauma

Cocaine use

Systemic lupus

Relapsing polychondritis 